\title{
SEKAR RARE SEBAGAI MEDIA PEMBELAJARAN NILAI ETIKA HINDU DI PENDIDIKAN ANAK USIA DINI
}

\author{
Ni Komang Wiasti ${ }^{\text {a }}$ \\ ${ }^{a}$ Institut Agama Hindu Negeri Gde Pudja Mataram \\ ${ }^{\text {a nikomangwiasti@yahoo.com }}$
}

(Diterima: 18 Juli 2021; Direvisi: 23 Juli 2021; Diterbitkan: 26 Juli 2021)

\begin{tabular}{|c|c|}
\hline Keywords: & Abstract \\
\hline $\begin{array}{l}\text { Sekar rare, } \\
\text { Learning Media, } \\
\text { Hindu ethical } \\
\text { values }\end{array}$ & $\begin{array}{l}\text { Dharmagita is a sacred religious song that is sung during } \\
\text { religious ceremonies. Within a specific scope, Dharmagita } \\
\text { can be sung at the level of formal, non-formal and informal } \\
\text { education. Because the benefits are very important for } \\
\text { Hindus, and even used to accompany dances that are profane } \\
\text { and sacred, children's play, and even worship to Ida } \\
\text { Sanghyang Widhi wasa. Sekar rare as a children's song that } \\
\text { has a cheerful character, as an accompaniment to children's } \\
\text { games today needs to be raised from an early age to an adult } \\
\text { level, with the aim of fostering social sensitivity, courtesy, } \\
\text { sradha bhakti, as Hindu ethical values. In reality, it is rarely } \\
\text { used by PAUD teachers because of the lack of references, and } \\
\text { they are still focused on implementing a complete } \\
\text { curriculum, so it needs to be awakened. Therefore, it is } \\
\text { necessary to study about sekar rare as a medium for learning } \\
\text { Hindu ethical values in PAUD. The method used in the } \\
\text { meaning of rare sekar is qualitative descriptive. Data analysis } \\
\text { refers to interpretive data and facts. There are several Hindu } \\
\text { ethical values contained in Dolanan, Gending Janger, and } \\
\text { Gending Sanghyang, namely divine values, compassion } \\
\text { values, national values, sradha bhakti values, and social } \\
\text { values. }\end{array}$ \\
\hline
\end{tabular}

Kata kunci:

Abstrak

Sekar rare,

Dharmagita merupakan nyanyian suci keagamaan

Media

Pembelajaran,

Nilai etika Hindu yang dilantunkan pada saat upacara keagamaan. Dalam lingkup yang spesifik Dharmagita dapat dinyanyikan pada pada jenjang pendidikan formal, non formal dan in formal. Oleh karena manfaatnya sangat penting dirasakan bagi umat Hindu, dan bahkan dipergunakan untuk mengiringi tarian 
yang bersifat profan dan sakral, dolanan anak, dan bahkan sampai pemujaan kehadapan Ida Sanghyang Widhi wasa. Sekar rare sebagai lagu anak-anak yang memiliki karakter ceria, sebagai pengiring permainan anak-anak saat ini perlu dibangkitkan mulai dari sejak dini sampai tingkat dewasa, yang tujuannya untuk menumbuhkan kepekaan sosial, sopan santun, sradha bhakti, sebagai nilai etika Hindu. Pada realitasnya sekar rare jarang diaplikasikan oleh guru PAUd karena minimnya referensi, dan masih terfokus pada penerapan kurikulum yang utuh, sehingga perlu dibagkitkan. Oleh sebab itu perlu pengkajian tentang sekar rare sebagai media pembelajaran nilai etika Hindu di PAUD. Metode yang dipergunakan dalam makna sekar rare adalah diskriftif kualitatif. Analisis data mengacu pada data dan fakta interpretatif. Terdapat beberapa nilai etika Hindu yang terkandung dalam Dolanan, gending Janger, dan Gending sanghyang adalah Nilai ketuhanan, Nilai Kasih sayang, nilai kebangsaan, nilai sradha bhakti, dan nilai sosial.

\section{PENDAHULUAN}

Dharmagita merupakan suatu nyanyian kebenaran, keadilan, yang dinyanyikan dalam pelaksanaan upacara agama Hindu sebagai pencurahan perasaan bakti dan pembimbing konsentrasi pikiran menuju suatu kebenaran (Midastra, \& Maruta, 2007). Oleh karena dharmagita mengandung ajaran agama, susila, tuntunan hidup, serta pelukisan kebesaran Tuhan dalam berbagai manifestasi-Nya, sehingga berperan penting dalam rangka meningkatkan kualitas kehidupan beragama di semua kalangan, dari anak-anak, remaja, dewasa dan bahkan para orang tua. Sebagaimana disebutkan dalam Kakawin Nitisastra bahwa pada zaman Kali (era keributan) tiba, maka tidak ada yang melebihi daripada harta kekayaan (uang).Orang-orang cenderung berebut harta kekayaan dan kekuasaan, tanpa menghiraukan moral dan etika. Norma-norma hukum diinjak-injak demi meraup kekayaan dan meraih kekuasaan (Suarka, 2003).

\section{Orang-orang}

akan

kebingungan, lupa kepada jati diri, lupa kepada saudara, dan tiada peduli kepada lingkungan dengan Dharmagita dapat mengubah suasana hati pembaca, pendengar, dan penikmatnya menjadi berbungabunga. Dalam hubungan inilah tubuh manusia, dharmagita dan bunga dapat dipahami sebagai sekar (bahasa Bali). Dharmagita (tembang) adalah sekar, dan tubuh manusia adalah juga sekar. Ketiganya merupakan yantra, tempat semayam dewa keindahan

Pada dimensi yang lain Dharmagita juga merupakan ungkapan rasa bhakti (sradha) kepada Ida 
Wasa.

Dharmagita diciptakan oleh penyair (pujangga) melalui beberapa tahapan. Pujangga (sang kawi) memulai karyanya dengan menyembah dewa pilihannya sebagai dewa keindahan, sebagai asal dan tujuan. Dewa itu dipandang menjelma dalam segala keindahan, baik di alam sakala, maupun alam niskala. Guna menemukan dewa keindahan yang menjelma di alam sakala, pujangga (sang kawi) mengembara, mengamati pertempuran, kecantikan wanita, menyusuri pantai, menjelajah gunung, hutan, sungai, dan lain-lain sambil berlaku tapa (Wiasti, 2021).

Dewa keindahan yang berada di alam niskala, berhasil ditemukan berkat laku tapa atau samadi pujangga (sang kawi). Dewa keindahan berkenan turun dan bersemayam di alam sakalaniskala, yakni di atas padma hati atau jiwa pujangga (sang kawi). Pujangga (sang kawi) berupaya mempersatukan diri dengan dewa tersebut. Persatuan itu merupakan sarana, yakni dengan persatuan pujangga (sang kawi) "bertunas keindahan" sehingga ia mampu menciptakan dharmagita, sekaligus tujuan yakni dengan menciptakan dharmagita, pujangga (sang kawi) berharap dapat mencapai pembebasan tertinggi (moksa). Sejalan dengan itu, maka dharmagita merupakan yoga sastra dan yoga keindahan (sundaram).

Dalam rangka yoga itu, dharmagita merupakan yantra, sebagai

candi tempat semayam dewa keindahan dan objek samadi bagi para pemuja dewa keindahan serta sebagai silunglung, bekal kematian. Dharmagita berfungsi membentuk dan menumbuhkan budi pekerti luhur (budi kaparamartan). Dalam Geguritan Purwasanghara, dijelaskan bahwa untuk dapat mengarungi samudra zaman Kali (era keributan) yang penuh badai itu, dapat ditempuh melalui kesusilaan budi, yakni keseimbangan antara akal budi dan kepekaan hati nurani. Dalam menyikapi berbagai situasi dan problema kehidupan, baik sebagai individu maupun masyarakat sosial, penggunaan akal budi harus diimbangi dengan kepekaan hati nurani. Salah satu cara untuk mengasah kepekaan rasa dan hati nurani adalah dengan membaca, menghayati, dan kemudian mengamalkan nilai-nilai yang terkandung dalam dharmagita.

$$
\text { Nyanyian (gita) suci }
$$

keagamaan yang diciptakan berdasarkan rasa. Di dalam rasa terjadi sublimasi emosi dari tataran psikologis ke tataran estetik. Dalam proses sublimasi emosi itu, emosi individual ditransformasikan menjadi rasa, yakni pengalaman estetik non individual, universal, mengatasai ruang dan waktu. Pengalaman estetik menjadi identik dengan pengalaman religius (Semadi, 2020). Dengan demikian, dharmagita merupakan perpaduan antara nilai seni (estetik) dan nilai moral. Dharmagita pun, berfungsi 
sebagai hiburan. Dengan melihat hakikat dharmagita sebagai sebuah nyanyian, maka unsur estetika (keindahan) merupakan hal esensial dalam dharmagita. Unsur estetika, secara intrinsik berfungsi sebagai pembangkit nilai estetika bagi dharmagita itu sendiri. Secara ekstrinsik akan memberikan efek estetis bagi penikmat dharmagita.

Efek estetis menyebabkan penikmat merasa terhibur oleh kandungan estetis dharmagita. Aspek estetis akan menyantuh budi. Oleh karena itu apabila pengucapan dharmagita dilakukan dengan benar dan tepat akan dapat menggetarkan hati nurani yang paling suci (budi). Budi nurani suci akan dapat menguasai pikiran atau manah. Pikiran (manah) yang kuat mengendalikan nafsu keinginan (indria) (Putra \& Astini, 2020). Nafsu keinginan (indria) yang terkendali dengan baik akan dapat mengarahkan perbuatan kita berpegang pada dharma (kebenaran). Perbuatan yang berpegang pada dharma akan menghasilkan pahala mulia berupa kehidupan bahagia lahir dan batin.

Dharmagita merupakan jenis sastra, yakni sastra tembang (gita). Dalam eksistensinya sebagai sastra tembang, dharmagita memiliki konvensi, baik konvensi sastra, konvensi bahasa, ataupun konvensi budaya (Sudarsana \& Arwani, 2018). Sebagai sastra tembang, dharmagita menggunakan bahasa sebagai media.
Sejalan dengan kedudukannya sebagai karya sastra tembang itu, maka bahasa dalam dharmagita menunjukkan ciriciri, antara lain khas yakni retorik, stilistik, bersifat khusus dan dianggap menyimpang dari bahasa sehari-hari. Kekhususan atau keistimewaan bahasa dalam sastra itu, memang merupakan faktor yang ditonjolkan. Hal itu berkaitan dengan eksistensi sastra sebagai seni yang meliputi retorika dan gramatika.

Penyair memiliki kekuatan persuasif yang diwujudkan melalui kemampuan untuk mengajar, memberi nikmat, dan menggerakkan. Bahasa dalam dharmagita merupakan sistem semiotik tingkat kedua, atau dalam bahasa Bali dinamakan basa makulit. Karya sastra menggunakan bahasa sebagai media dan bahasa itu merupakan sistem semiotik. Bahasa sebelum digunakan penyair, sudah merupakan sistem tanda, sistem semiotik. Jenis-jenis bahasa yang digunakan dalam dharmagita, meliputi bahasa Sanskerta, bahasa Jawa Kuna, bahasa Tengahan, dan bahasa Bali seperti yang terdapat pada gagendingan (Wiasti, 2021).

Gending rare mencakup berbagai jenis lagu anak-anak yang bernuansa permainan. Jenis tembang ini pada umumnya memakai bahasa Bali sederhana bersifat dinamis dan riang gembira, sehingga dapat dilagukan dengan mudah dalam suasana bermain bergembira. Biasanya tiap lagu dilengkapi sebuah permainan 
yang memiliki tema, tetapi ada juga berdiri sendiri sebagai lagu rakyat yang bentuknya sangat sederhana. Lagu anak-anak maupun lagu rakyat tidak terlalu terikat oleh hukum/uger-uger pada lingsa. Sekar rare ditembangkan sesuai dengan irama laras pelog. Gending rare dinyanyikan oleh kalangan anak-anak ketika bermain karena sangat dekat dengan kehidupan dunia anak-anak yang menggambarkan suasana gembira atau senang yaitu seperti : guak maling taluh, meong-meong, juru pencar, putri cening ayu, dadong dauh dll. Dolanan adalah salah satu permainan yang biasa dilakukan oleh anak-anak, yang berfungsi untuk menghibur dan menumbuhkan daya kreativitas anak. Adapun manfaat dari sekar rare adalah sebagai berikut : a) menghayati ajaran agama secara mendalam, sehingga perasaan, pikiran, dan budhinya menjadi halus ;b) menggetarkan alam rasa dan meningkatkan sradha bhakti kepada Ida sanghyang Widhi Wasa serta prabhawanya (Sugimawa, 2009). Sehubungan dengan pelaksanaan Dharmagita dalam upacara agama Hindu,renungkanlah mantra berikut:

"Gayo sa sasravartani" (Sama Weda 8.29) Artinya; Kami menyanyikan mantra-mantra Samaweda dalam ribuan cara. "Ubhe vacau vaditi samaga iva, gayatram ca traistubham canu rajati"(Regweda II.43.1) (Pudja, G., \& Sadia, 1979).

Artinya; Burung menyanyi dalam nada-nada seperti seorang pelafal Sama Weda, yang mengidungkan mantra dalam irama Gayatri dan Tristubh. Dengan sloka tersebut dapat dimaknai bahwa, dengan menyanyikan lagu-lagu keagamaan merupakan media Implementasi dari ajaran weda, sebagai sabda suci Tuhan yang mengandung ajaran kebenaran (dharma). Dengan memaknai konsep tersebut diatas maka begitu pentingnya pembentukan dasar yang kuat dalam belajar agama pada Pendidikan anak usia dini sebagai strategi pembangunan sumber daya manusia yang berkualitas.

Pendidikan anak usia dini menentukan sejarah perkembangan anak selanjutnya serta membentuk pondasi dasar kepribadian. Anak yang mendapat pendidikan sejak dini dapat meningkatkan kesejahteraan fisik, dan mental sehingga menentukan kecerdasannya kelak dikemudian hari, Masa usia dini menjadi masa golden age karena dalam perkembangan otak manusia, tahap perkembangan anak usia dini menempati posisi yang paling penting (Wiguna, \& Ekaningtyas, 2021). Materi pembelajaran yang bersifat aplikatif, enjoyble, dan mudah ditiru sebagai media belajar perlu mendapat sentuhan sebagai pengembangan sikap dan prilaku yang positif yang merupakan nilai etika Hindu yang utama (Wiguna, 2020). Makna etika dalam agama Hindu dikatakan sebagai ilmu yang mempelajari tentang tata nilai, hal yang baik dan buruknya suatu perbuatan manusia, mengenai apa 
yang harus dikerjakan dan apa yang harus ditinggalkan, sehingga dengan demikian akan tercipta kehidupan yang rukun, aman dan damai dalam kehidupan manusia. Di dalam hal tersebut perlu suatu langkah strategi sebagai media dalam mewujudkannya.

Media pembelajaran adalah sebuah cara yang dilakukan oleh guru dalam mentransformasi ajaran-ajaran agama Hindu agar mudah dipahami dan dimengerti anak, seperti misalnya proses kegiatan pendidikan anak usia dini. Ajaran- ajaran yang dimaksud seperti Tattwam Asi, Sradha Bhakti, Kasih sayang (Asih), dan cinta tanah air. Dengan sambil menyanyi maka pembelajaran akan menjadi lebih menarik dan menyenangkan bagi anak. Banyak cara dalam memberikan pembelajaran pada anak usia dini, terlebih mengajarkan nilai agama agar mudah dipahami dan dimengerti.

Menurut (Eka Mahendra, 2020) menyatakan bahwa penerapan ajaran agama Hindu di sekolah melalui 6 cara yang disebut dengan Sad Dharma yaitu : 1) Dharma wacana ;2) Dharmagita ;3) Dharma sadhana ;4) Dharma Yatra ;5) Dharmatula ;6) Dharma santih. Keenam hal tersebut sebaiknya dilaksanakan secara berkesinambungan, dari hal sederhana sampai dengan kompleks. Ajaranajaran konsep Hindu terus di sosialisasikan dan disampaikan dengan cara dan metode yang tepat, menurut tingkat usia. Hal tersebut akan memberikan manfaat terhadap pembentukan karakter, sikap prilaku anak dimasa yang akan datang seperti memiliki jiwa yang tangguh, sopan santun, tanggungjawab, percaya diri, saling menghargai, disiplin, dan memilikki sradha bhakti yang kuat, serta mampu beradaptasi pada era kekinian.

Fenomena yang terjadi bahwa pada lembaga pendidikan anak usia dini masih sangat jarang menyelipkan pembelajaran megending bali atau gending rare karena para pendidik menerapkan kurikulum PAUD secara utuh dengan menyanyikan lagu-lagu anak-anak terkait tema, sehingga dengan kebiasaan yang dilakukan guru, konsep ajaran-ajaran Hindu belum dikenal sejak dini oleh anakanak. Pada hal yang lain karena kurangnya sumber referensi di sekolah. Berdasarkan pemaparan tersebut di atas maka yang akan diulas dalam artike ini adalah Bagaimanakah makna sekar rare sebagai media pembelajaran nilai etika Hindu pada Pendidikan anak usia dini?

Adapun tujuan penulisan ini adalah sebagai bahan referensi dan acuan bagi perkembangan ilmu pengetahuan tentang Dharmagita khususnya sekar rare (gagendingan), yang merupakan budaya Hindu yang perlu dilestariakan keberadaannya. Kedepannya dapat diterapkan oleh para guru PAUD dalam proses awal pembelajaran sebagai media menstimulasi mood (motivasi) belajar anak. 


\section{METODE}

Metode dalam penelitian ini menggunakan diskriftif kualitatif. Analisis data mengacu pada data dan fakta interpretatif, karena kandungan isinya, diperoleh dengan cara mengamati, melantunkan, memaknai setiap baris narasinya, dan menginterpretasikannya, sehingga mempermudah proses menganalisisnya, dan bisa dituangkan dalam bentuk artikel ilmiah ini. Dalam pembahasan selanjutnya akan diuraikan tentang arti sekar rare, Jenisjenisnya dan Makna yang terkandung dalam sekar rare tersebut.

\section{PEMBAHASAN}

\subsection{Pengertian Sekar rare}

Pengertian sekar rare merupakan tembang tertua di Bali yang tidak memiliki aturan yang jelas, dipakai mengiringi gambelan, sajaknya bebas, yang menyelipkan ajaran-ajaran etika yang sangat mendalam. Di saat ini ketika ingin menyampaikan ajaran agama melalui ceramah, atau penyuluhan masyarakat akan bosan dan jenuh mendengarkan tetapi dengan menyanyi akan menjadi lebih menarik, dan membahagiakan kehidupan anak (Pasek, 2002). Sedangkan Sekar rare adalah nyanyian lagu yang disebut gagendingan, biasanya dinyanyikan oleh anak-anak disaat sedang bermain dengan orang tuanya, teman-temannya yang bersifat bahagia, ceria dan menggembirakan, disamping itu juga dipakai mengiringi gambelan dengan menggunakan bahasa daerah Bali yang bersifat dinamis dan riang.

Terdapat perbedaan antara sekar rare dan sekar alit, kalau sekar rare utuh mengikuti pola permainan, sedangkan sekar alit terdapat kunci, cara menyanyikannya dengan mengikuti pada lingsa dan purwakanti, yang dikenal dengan macapat, membaca suku kata empat-empat. Biasanya sekar rare dalam Hindu terdiri dari dolanan, gending janger, Gending sanghyang. Sekar rare dalam bait liriknya mengandung pesan cerita tentang tingkah laku susila dan pengetahuan

\subsection{Jenis-Jenis Sekar Rare}

Jenis diartikan dalam ragam, macam variasi, atau bagian-bgiannya, yang dikelompokkan terdiri dari yaitu : 1. Dolanan

Dolanan merupakan salah satu jenis sekar rare yang memiliki sifat ceria, gembira dan lucu, mengandung etika susila (budhi pekerti) fungsinya untuk mengembangkan potensi, bakat anak, serta nasehat yang dapat mengubah pola prilaku anak menjadi anak yang baik.

2. Gending Janger

Gending janger atau jejangeran adalah suatu nyanyian yang dibawakan oleh penari janger atau kecak, yang merupakan bagian dari sekar rare. Tema dari gending janger beraneka ragam, mengikuti perkembangan jaman.

3 Gending Sanghyang 
Sanghyang berarti mulia atau yang dimuliakan, atau berarti Dewata, yakni sinar suci atau prabhawa Ida sanghyang Widhi Wasa. Gending sanghyang dilantunkan oleh anak-anak yang belum memasuki akil balik, atau mensturasi seperti sanghyang jaran.

Beberapa contoh Gagendingan (Sekar rare) (Sukertiasih, L., Wirani, I. A. S., \& Martha, 2015).

a. Bebeke putih jambul, makeber kaja kanginan

Teked kaja kangin, ditu ya tuwun mekelang

Briyak briyuk mesileman $2 x$

Artinya : itik kepala putih jambul terbang ke arah timur laut, sampai ditimur laut, disana turun semua, bersamasama mandi dan menyelam.

Maknanya adalah bebeke putih jambul adalah lambang orang- orang yang berjiwa suci, terbang menuju surga diyakini sebagai ulon atau munculnya sang surya, bersama-sama merasakan dan menikmati kebahagiaan, Sifat itik perlu diteladani, tidak pernah bertengkar, kasih sayang, dan pandai memilah makanan yang satwik.

b. Putri cening ayu

Putri cening ayu, ngijeng cening jumah,

meme luas malu, kepeken meblanja,

apang ada darang nasi.
Meme tiang ngiring, ngijeng cening jumah, sambilang mepunpun, ngijeng cening jumah dimulehne ye gapgapin.

Makna dari lagu putri cening ayu, merupakan gambaran kasih sayang seorang ibu kepada anaknya. Diharapkan agar ketika ibunya pergi meninggalkan rumah maka si anak membantu pekerjaan orang tuanya dirumah, Dengan demikian dapat menumbuhkan kebiasaan anak menjadi bertanggungjawab.

c. Semut semut api

Semut-semut api kija ambain muleh

Tembok bolong saling atat saling pentil

Ketipat nasi pasil benne dongkang kipa

Enjok-enjok jit metegil

Makna dari lagu tersebut, semut api adalah situasi ketika orang-orang mudah diliputi rasa marah, benci, dendam. Rasa tersebut merupakan bagian dari sad ripu (musuh) bagi setiap orang. Dalam kekawin ramayana, disebutkan bahwa rogadi musuh maparo, tonggwanya tan madoh ring awak, artinya bahwa musuh terbesar ada dalam diri setiap orang. Sehingga perlu dikendalikan, agar tidak menimbulkan kesengsaraan.

d. Made cenik

Made cenik lilig montor dibisanja $2 x$

Montor Badung ke Gianyar $2 x$ 
Gedebege muat batu

Batu cina bais lantang cungguh barak $2 x$

Mangumbang-umbang I Codet

$2 x$

Maknanya agar kita sebagai manusia, agar kreatif, dan mampu untuk beradaptasi dijaman sekarang, menguasai ilmu pengetahuan dan teknologi. Dalam Bhagawadgita IV.34, Pelajarilah ilmu pengetahuan dengan bertanya-tanya dan dengan pelayanan, orang yang melihat kebenaran itu akan memberikan petunjuk bagimu pada pengetahuan itu. Nitisataka, 12 juga menyebutkan bahwa dengan ilmu pengetahuan itu sangat mensejahterakan. Dengan demikian betapa pentingnya ilmu pengetahuan untuk kebahagiaan hidup.

e. Juru Pencar

Juru pencar juru pencar

Mai Jalan mencar ngejuk ebe

Be gede-gede be gede-gede

Di sowane ajaka liu

Makna lagu juru pencar, adalah memberikan isyarat untuk lebih bijak dalam memilih suatu profesi yang ditekuni. Diharapkan lebih mengenal bakat, potensi, dan keahlian masingmasing personil, untuk menuju kesuksesan. Sesungguhnya manusia ketika lahir sudah dibekali bakat, ketrampilan, maka perlu diasah dan dilatih sejak dini, agar diketahui apa yang menjadi bakatnya. Pengasahan bakat dilakukan dengan beberapa cara misalnya dengan mengikuti pelatihanpelatihan sesuai bidang keahliannya. Bakat diperlukan sebagai penunjang menekuni suatu profesi yang digeluti agar lebih profesional dibidangnya.

\section{f. Merah Putih}

Merah Putih benderan titiange

Berkibaran dilangite terang galang

Nika lambang jiwan rakyat Indonesia

Merah bani medasar atine suci Pusaka adi leluhur jaya sakti

Merah putih benderan titiange

Makna lagu merah putih, mengartikan bahwa sebagai bangsa Indonesia patut merasa bangga kepada para pahlawan yang telah berjuang untuk kemerdekaan Indonesia, serta melambangkan rasa cinta dan hormat pada tanah air. Bendera merah putih yang kita warisi memiliki arti sebagai lambang kesucian (putih) dan keberanian (merah). Kesucian dapat diraih dengan berbuat yang benar, berpikir yang benar dan berkata yang benar, sedangkan keberanian diperlukan untuk menegakkan kebenaran, Satyam paro dharma. satyam eva jayate (Kejujuran adalah dharma, kebenaran akan menang).

g. Sanghyang Widhi

Sanghyang widhi ngardi jagad sami

Miwah dagingnya sekancan mauripe

Tejan ida ngebekin jagat

Mraga agung hana tan hana 
Patut tityang subakti ring Hyang Wisesa

Melaksana manut ring daging agama

Makna lagu sanghyang Widhi
merupakan salah satu cara
memuliakan akan kebesaran dan
kemahakuasaannya atas segala isi alam
semesta. Sebagai manusia sebaiknya
berjalan sesuai dengan ajaran dharma
(kebenaran), demi tercapainya tujuan
agama Hindu Moksartham ya ca iti
dharma. Dengan Saling asah, asih, dan
asuh.

h. Don Dapdape

Don Dapdape don dapdape lum-lum gading

Ya lumlum gading ya

lumlum gading

Panak panak biyu panak biu

di kedaton

Panak biu dikedaton panak

biu di Kedaton

Kaja-kaja luas ka Gunung

Kaja-kaja mbok nyoman

luas ka gunung

Biu sangket jekjek sampi di maliling $2 x$

Meli jegog meli jegog di sablanga mimbuh suling $2 x$

Makna melambangkan suka cita para anak laki-laki dan perempuan, diharapkan untuk saling menghormati, dan menghargai, menciptakan kerukunan. Memahami agar pada kehidupan kehadiran laki-laki dan perempuan untuk saling melengkapi, saling membutuhkan antara satu dengan yang lainnya.

i. Sekar Emas

Sekar disekar emas mangreronce

Sekar disekar emas mangreronce

Sekar disekar di sangga langit

Soyor kangin soyor kauh layak-layak

Makna dari lagu sekar emas, sebagai pelestarian budaya Hindu yang adi luhung, Hindu dihargai, dihormati, karena aneka budaya, baik berupa seni tari, kidung dan upacara agamanya, sehingga lebih semarak, dan hidup. Jika dianalogikan seperti emas, selalu bersinar walaupun dalam lumpur.

Jika mengacu pada proses pembelajaran di PAUD yang menekankan pada belajar sambil bermain, maka seorang guru agar selektif, dan kreatif memilih lagu-lagu gagendingan yang kiranya memiliki keterkaitan erat dengan tema-tema yang terdapat dalam kurikulum PAUD. Dengan hal tersebut maka magending sebagai tradisi lama budaya luhur Hindu, dapat diajegkan keberadaannya. Terdapat 6 aspek capaian perkembangan pada anak usia yang meliputi : a) aspek perkembangan agama dan moral ; b) aspek perkembangan fisik motorik;c) aspek perkembangan sosial dan emosional ; d) aspek perkembangan seni; e) aspek perkembangan bahasa ; f) aspek 
perkembangan

kognitif

(Permendikbud, 2014). Sedangkan tema-tema yang terdapat dikurikulum PAUD terdiri dari : diriku, keluargaku, lingkungan,Kebutuhanku, Binatang, tanaman, alam semesta, rekreasi, pekerjaan, air, api dan udara, tanah airku

\subsection{Nilai Etika yang terkandung dalam Sekar rare}

Nilai dimaknai sebagai sesuatu kecendrungan prilaku yang berawal dari gejala-gejala psikologis seperti : hasrat, motif, sikap, kebutuhan, dan keyakinan yang dimiliki secara individual sampai pada wujud tingkah lakunya yang unik (Rohmat, 2011) sedangkan etika diartikan dengan tata cara atau pola berprilaku yang baik dan benar menurut ajaran Hindu (Hasan, 1988). Dari pengertian diatas yang dimaksudkan dengan nilai etika pada tulisan ini adalah sebagai salah satu cara berprilaku agar sesuai dengan norma yang berlaku dimasyarakat. Ada beberapa nilai yang terkandung dalam sekar rare adalah sebagai berikut

\section{Nilai Ketuhanan}

Ketuhanan diartikan sebagai sifat-sifat tuhan atau yang berhubungan dengan Tuhan (Ida Sanghyang Widhi Wasa). Sifat tuhan pada anak usia dini sangat sulit untuk digambarkan sehingga melalui lagu keagamaan, lebih mudah dipahami, seperti personifikasi ke dalam banyak nama, atribut, dan tugas fungsinya.
Kepercayaan terhadap Tuhan dengan manifestasinya yang jamak, telah menginspirasi seluruh rangkaian dalam Hindu, baik dalam kaitannya dengan sepanjang hidup individu, menjaga kelestarian alam, keselamtan dan kebahagiaan, konsistensi pikiran, perkataan dan perbuatan menetukan manusia mencapai moksa (penyatuan dan pembebasan).

\section{Nilai kasih sayang (cinta} kasih)

Kasih sayang atau cinta kasih (prema) merupakan dua pasang kata dimana satu dengan yang lainnya saling berhubungan, secara harfiah kata cinta mengandung pengertian suka sekali, perasaan sayang, terpikat, ingin dan berharap, rindu sekali. Diartikan bahwa suatu kerinduan yang mendalam yang muncul dari hati yang paling dalam sebagai wujud perasaan senang, bahagia, tenang, demi terwujudnmya kedamaian (santih lan jagadhita)

\section{Nilai cinta tanah air (kebangsaan)}

Cinta tanah air, merupakan cinta kebangsaan yang dimiliki oleh seluruh rakyat Indonesia. Sebagai bangsa patut merasa bangga akan seni budaya luhur bangsa, baik berupa lagu kebangsaan, bendera merah putih, lagu-lagu, dan seni tradisional. Budaya Indonesia perlu dikenang, dan dihargai keberadaannya, sehingga dikenang dan dibangkitkan mulai dari anakanak, remaja, dewasa dan para orang tua, atau seluruh bangsa Indonesia agar kokoh keberadaannya. 


\section{Nilai sradha bhakti}

Sradha bhakti artinya

keyakinan dan rasa percaya yang dimiliki oleh setiap penganut Hindu akan ajaran agamanya. Keyakinan tumbuh dari pemahaman yang baik dan benar terhadap makna, simbulsimbul yang dimiliki Hindu. Dengan memahami dan mencermati setiap kata yang terkandung dalam lirik lagu sekar rare akan mampu menterjemahkan kandungan makna dalam gagendingan tersebut. Bagi usia anak pada pendidikan anak usia dini tentu akan lebih mudah, untuk mereka pahami, karena menggunakan bahasa Bali, sehingga merupakan pondasi dan benteng diri yang kuat tentang ajaran Hindu.

\section{Nilai Sosial}

Nilai sosial adalah berbagai prinsip, anggapan maupun keyakinan yang berlaku dalam tata kehidupan bermasyarakat. Dan nilai sosial juga merupakan suatu prilaku atau tindakan, individu yang dianggap baik oleh kebanyakan orang. Dalam gagendingan tersebut memiliki nilai sosial artinya bahwa bagaimana seorang anak, mampu terlibat dalam situasi sosial yang wajar, misalnya tolong menolong, memupuk kerjasama, dapat bermain dengan teman sebaya, dan mampu menciptakan kondisi yang rukun.

\section{SIMPULAN}

Gagendingan atau yang
disebut dengan sekar rare,

merupakan lagu anak-anak yang dipergunakan sebagai pengiring permainan tradisional, agar lebih semarak. Secara umum dengan seiring perkembangan ilmu pengetahuan dan teknologi para guru pendidikan anak usia nampaknya perlu menerapkan gagendingan sebagai proses awal kegiatan yang berfungsi untuk memotivasi dan memperkenalkan budaya Hindu yang sangat luhur. Dengan memberikan sekar dalam makna kiasan akan memberi arti dan mewujudkan kedamaian bagi setiap insan peserta didik dan pendidik, maka karakter etika sopan santun dapat dibentuk dan dikembangkan sejak dini sebagai pondasi yang kokoh dalam mengembangkan kepribadian anak. Kandungan nilai ketuhanan, kasih sayang, Cinta tanah air, sradha bhakti dan nilai sosial yang begitu mendalam setiap barisnya akan mampu merubah dan memupuk semangat belajar anak untuk memahami ajaran agama Hindu yang dikandungnya dan secara tidak langsung konsep pembelajaran yang menyenangkan buat anak akan semakin kuat.

\section{DAFTAR PUSTAKA}

Eka Mahendra, I. (2020). Developing Character of Disability Students through Picture and Picture 
Models with Sad Dharma Method.

International Journal of Psychosocial Rehabilitation, 24(6).

Hasan, F. (1988). Kamus Besar Bahasa Indonesia (KBBI) Edisi ke-2. Departemen Pendidikan dan Kebudayaan. Jakarta: Balai Pustaka. Ida Bagus Alit Arta Wiguna, K. A. T. R. D. (2020). Strategi Guru Dalam Peningkatan Mutu Pembelajaran Etika Hindu. Jurnal Penjaminan Mutu, 6(2), 210-220 https://doi.org/DOI:

http://dx.doi.org/10.25078/jpm. v6i2.1449

Midastra, I. W., \& Maruta, I. K. (2007). Widya Dharma Agama Hindu SMP kls 9. Ganeca Exact.

Pasek, G. (2002). Aneka Rupa Gending Bali. Penerbit paramitha Surabaya.

Tentang Standar Nasional Pendidikan Anak Usia Dini., Pub. L. No. Permendikbud, R. I. No 137 Tahun 2014. (2014).

Pudja, G., \& Sadia, W. (1979). Sama Weda. Jakarta: Departemen Agama RI.

Putra, A. A., \& Astini, K. Y. W. (2020). KONSEP KETUHANAN MENURUT PRESPEKTIF SAMKYA DARSANA. Vidya DarÅ an: Jurnal Filsafat Hindu, 1(2).

Rohmat, M. (2011). Mengartikulasikan Nilai Pendidikan.

Semadi, G. N. Y. (2020). Brahma Cakra:
Sebuah Tarian Kosmik. Nilacakra.

Suarka, I. N. (2003). Hakekat dan JenisJenis Dharmagita serta Peranannya dalam Kehidupan Masyarakat Bali. In Naskah Seminar Dharmagita, 1(1).

Sudarsana, I. K., \& Arwani, G. (2018). Internalisasi Pendidikan Karakter Melalui Pelaksanaan Dharmagita Pada Sekaa Teruna. ... Jurnal Ilmu Agama.

Sugimawa, I. W. (2009). Materi Pokok Dharmagita. Direktorat Jenderal Bimbingan Masyarakat Hindu.

Sukertiasih, L., Wirani, I. A. S., \& Martha, I. N. (2015). SESELEH KAWIGUNAN (FUNGSI) LAN SUKSMAN (MAKNA) GENDING RARE RING BUKU EDISI GENDING-GENDING BALI (SEKAR RARE) DRUWEN DINAS PENDIDIKAN KABUPATEN BULELENG WARSA 2003. Jurnal Pendidikan Bahasa Bali Undiksha, 2(1).

Wiasti, N. K. (2021). Bahan ajar Dharmagita. IAHN Gde Pudja Mataram.

Wiguna, I. B. A. A., \& Ekaningtyas, N. L. D. (2021). STRATEGI ORANG TUA DALAM MENDAMPINGI ANAK USIA DINI BELAJAR DARING DI RUMAH. Pratama Widya: Jurnal Pendidikan Anak Usia Dini, 6(1), 86-95. 